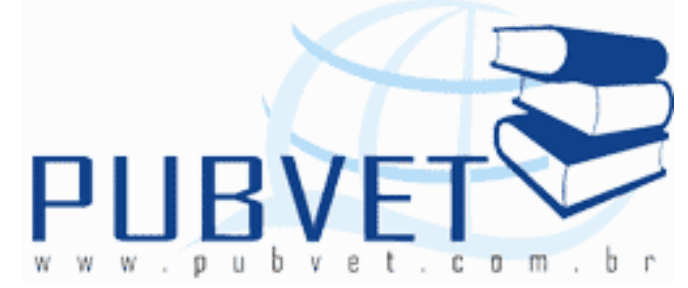

PUBVET, Publicações em Medicina Veterinária e Zootecnia.

\title{
Competição de variedades de cana-de-açúcar para a alimentação de ruminantes em Presidente Médici, Rondônia
}

Claudio Ramalho Townsend ${ }^{1}$, Newton de Lucena Costa², Ricardo Gomes de Araújo Pereira ${ }^{1}$, Francelino Goulart da Silva Netto ${ }^{3}$, João Avelar Magalhães ${ }^{4}$, Braz Henrique Nunes Rodrigues ${ }^{5}$

${ }^{1}$ Zootecnista, D.Sc., Embrapa Rondônia. Porto Velho, RO.

${ }^{2}$ Eng. Agrônomo, M.Sc., Embrapa Roraima. Boa Vista, RR. Doutorando em Agronomia, UFPR.

${ }^{3}$ Médico Veterinário, M.Sc., AGEVISA. Porto Velho, RO.

${ }^{4}$ Médico Veterinário, D.Sc., Embrapa Meio-Norte. Parnaíba, PI.

${ }^{5}$ Eng. Agrícola, D.Sc. Embrapa Meio-Norte. Parnaíba, PI.

\section{Resumo}

Avaliou-se o desempenho agronômico das variedades de cana-de-açúcar (RB 72-454, RB 76-5418, RB 78-5148, RB 73-9359, RB 83-5486, SP 71-1406, SP 79-1011, CB 45-3, CB 47-355 e NA 56-79 e uma variedade "Local", como testemunha) introduzidas em Presidente Médici, Rondônia. O delineamento experimental foi em blocos casualizados com três repetições. O plantio foi realizado em novembro de 1999 e a colheita em junho de 2001. As plantas apresentaram altura média de 417 cm, RB 83-5486 apresentou menor altura e RB 73-9359 a maior $(P<0,01)$ em relação às demais variedades. RB 78-5148 apresentou o maior teor de MS e RB 72-454 a menor $(P<0,01)$. O maior nível 
TOWNSEND, C.R. et al. Competição de variedades de cana-de-açúcar para a alimentação de ruminantes em Presidente Médici, Rondônia. PUBVET, Londrina, V. 6, N. 28, Ed. 215, Art. 1430, 2012.

de ${ }^{\circ}$ Brix foi obtido com a RB 83-5486, que não diferiu da NA 56-79, SP 791011, SP 71-1406, RB 73-9359, RB 78-5148 e RB 76-5418 $(\mathrm{P}<0,01)$. Os rendimentos médios de MV e MS foram de 208 e 55 t/ha, respectivamente, com RB 73-9735 atingindo os maiores, não diferindo da RB 72-454, RB 785148, RB 71-1406, SP 79-1011, CB45-3, CB 47-355 e NA 56-79 (P>0,01). As plantas apresentaram valores médios de $88,7,4$ e $1 \%$ de caules, ponteiras, folhas verdes e secas, respectivamente. A SP 79-1011 se destaca por alta produtividade conciliada a satisfatórios teores de sólidos solúveis (açúcar) e participação de colmos, podendo ser recomendada para cultivo nas condições edafoclimáticas de Presidente Médici, Rondônia.

Palavras-chave: Amazônia Ocidental, avaliação agronômica, Saccharum

\title{
Competition varieties of sugarcane for ruminants feeding in Presidente Médici, Rondônia
}

\begin{abstract}
The agronomic performance of sugarcane varieties (RB 72-454, RB 78-5148, RB 73-9735, RB 73-9359, RB 83-5486, SP 71-1406, SP 79-1011, CB 45-3, CB 47-355, NA 56-79 and test) introduced in Rondônia, Brazil was evaluated. It was used a randomized blocks design, with three replications. The plantation was carried out in November of 1999 and the harvesting occurred in June of 2001. The plants presented average height of $417 \mathrm{~cm}$. The RB 83-5486 presented smaller height and RB 73-9359 was higher than another varieties. RB 78-5148 presented the largest DM content and RB 72-454 the smallest $(P<0.01)$. The highest level of ${ }^{\circ}$ Brix was obtained with the RB 83-5486, which did not differ from NA 56-79, SP 79-1011, SP 71-1406, 73-9359 RB, RB and RB 78-5148 76-5418. The average yield of GM and DM were of 208 and 55 t/ha, respectively, with $R B$ 73-9735 reaching the largest ones, not being different of RB 72-454, RB 78-5148, RB 71-1406, SP 79-1011, CB45-3, CB 47355 and NA 56-79 ( $P>0.01)$. The plants showed average values of $88,7,4$ and $1 \%$ of stems, tip, green and dry leaves, respectively. The SP 79-1011 stands
\end{abstract}


TOWNSEND, C.R. et al. Competição de variedades de cana-de-açúcar para a alimentação de ruminantes em Presidente Médici, Rondônia. PUBVET, Londrina, V. 6, N. 28, Ed. 215, Art. 1430, 2012.

out from the others, because it has high productivity reconciled to satisfactory soluble solids (sugar) and participation of stems, may be recommended for cultivation in environmental conditions Presidente Médici, Rondônia.

Keywords: Amazonian Western, agronomic evaluation, Saccharum

\section{Introdução}

Com um rebanho superior a mais de 11,5 milhões de cabeças, a pecuária, tanto de corte como de leite, é uma das atividades econômicas mais importantes de Rondônia. No entanto, ainda prevalecem baixos índices de produtividade, quando comparados aos obtidos em outras regiões do país e do mundo, como por exemplo, a taxa de $5 \%$ de desfrute anual do rebanho de corte e a produção leiteira de 580 l/vaca/ano (IDARON, 2011).

As pastagens cultivadas representam o principal suporte alimentar do rebanho bovino, contudo apresentam marcada estacionalidade na produção, implicando em déficit quantitativo e qualitativo da forragem ofertada, durante a estação seca (junho a setembro), representando um dos principais fatores que contribuem para o baixo desempenho zootécnico do rebanho e queda na capacidade de suporte das pastagens. Uma das alternativas para contornar esta situação seria o uso de suplementação alimentar do rebanho durante o período crítico (COSTA et al., 1996).

Neste sentido cana-de-açúcar (Saccharum officinarum L.) surge como uma alternativa. Originária do sudeste asiático é uma gramínea perene que se destaca entre as demais devido à sua múltipla utilidade, podendo ser empregada como matéria prima para agroindústria e in natura, sob a forma de forragem, para alimentação animal. É relativamente fácil de ser implantada e manejada, com baixo custo, podendo atingir rendimentos superiores a $120 \mathrm{t}$ de matéria verde $(\mathrm{MV}) / \mathrm{ha}, 30 \mathrm{t}$ de matéria seca (MS)/ha e $15 \mathrm{t}$ de nutrientes digestíveis totais (NDT)/ha, obtidos em um único corte. Normalmente sua maturação ocorre durante o período seco, quando a oferta de forragem das pastagens é limitante à produção animal. A formação do canavial representa 
TOWNSEND, C.R. et al. Competição de variedades de cana-de-açúcar para a alimentação de ruminantes em Presidente Médici, Rondônia. PUBVET, Londrina, V. 6, N. 28, Ed. 215, Art. 1430, 2012.

uma medida apropriada e econômica para suplementação alimentar do gado, neste período (GANEM, 1997; CAMPOS et al., 2009).

Ao contrário das outras gramíneas tropicais, a cana-de-açúcar mantém seu valor nutritivo praticamente inalterado por períodos de tempo relativamente longos (12 a 18 meses), devido ao aumento da concentração de sacarose, com o avanço na idade da planta, pois este carboidrato apresenta digestibilidade próxima a 100\%, havendo simultaneamente redução na concentração de componentes da parede celular, que apresentam baixa digestibilidade (PEIXOTO, 1986).

Um dos principais fatores que limitam a utilização da cana-de-açúcar na alimentação de ruminantes é a baixa degradabilidade ruminal da fibra, o que eleva o tempo de permanência no rúmen, refletindo na diminuição do consumo voluntário dos animais, e consequentemente na ingestão de energia. Outro fator limitante são os baixos teores de proteína bruta (PB), que oscilam entre $1,8 \mathrm{e}$ $5,8 \%$ da MS, uma vez que níveis inferiores a $7 \%$ restringem a produção animal, em função do baixo consumo voluntário, menor digestibilidade da forragem e balanço nitrogenado negativo, principalmente com relação aos aminoácidos essenciais (RODRIGUES et al., 1997; PINTO et al., 2003; SILVA et al., 2007; SIQUEIRA et al., 2011; DOMINGUES et al., 2012).

Segundo Torres \& Resende (1997), a seleção de variedades adaptadas e produtivas constitui um dos fatores mais importantes na cultura da cana. Dentre as principais características agronômicas desejáveis para a escolha de uma cultivar, destacam-se: alto índice de produtividade, elevado teor de açúcar (sacarose), boa capacidade de rebrota, ausência de florescimento ou "flechamento", fácil despalha ou ausência de "joçal" e resistência a pragas e doenças, as quais são marcadamente afetadas pelas condições ecológicas da região de plantio.

Torres et al. (2001) avaliaram 13 variedades de cana-de-açúcar nas condições edafoclimáticas de Coronel Pacheco-MG. Os resultados médios de nove safras (1993 a 2001) demonstraram que a produção de MV foi crescente da primeira (186 t/ha) para a segunda (221 t/ha) colheita, se mantendo 
TOWNSEND, C.R. et al. Competição de variedades de cana-de-açúcar para a alimentação de ruminantes em Presidente Médici, Rondônia. PUBVET, Londrina, V. 6, N. 28, Ed. 215, Art. 1430, 2012.

próxima a 200 t/ha nos anos de 1995, 96, 98 e 99, havendo decréscimos nas safras de 1997, 2000 e 2001, com rendimentos próximos a 150 t de MV/ha. A produtividade média das nove safras foi de $187 \mathrm{t}$ de $\mathrm{MV} / \mathrm{ha}$, oscilando entre 217 (RB 73-9735) e 162 t/ha (SP 71-0799), com as variedades CB 45-3, SP 71-1406 e CO 419 produzindo entre 190 e 211 t de $M V /$ ha, enquanto que $C B$ 47-355, NA 56-79, SP 70-1143, SP 71-6163, RB 72-454, RB 73-9359, RB 765418 e RB 78-5148 renderam entre 170 a 190 t de MV/ha. Quanto à época de colheita, as variedades RB 76-5418, NA 56-79 e SP 70-1143, foram consideradas precoces (maio a julho) e as CB 45-3 e RB 72-454 tardias (agosto a novembro), enquanto que as demais variedades foram médias a tardias, iniciando $o$ corte em junho/julho e estendendo-se até setembro/outubro.

Ao testarem atributos qualitativos de 11 variedades de cana-de-açúcar, cultivadas em um Latossolo Vermelho-Escuro Eutrófico, Rodrigues et al. (1997) constataram que aos 15 meses de crescimento, a participação de colmos nas plantas oscilou entre $73 \%$ ( CB 47-355) e $88 \%$ (RB 76-5418), a de folhas 11 \% (RB 76-5418) e $27 \%$ (CB 47-355), havendo relação direta entre os teores de fibra detergente neutra (FDN) da planta e a participação de folhas e inversa com as de colmos. No entanto, quanto maior a participação de colmos, a quantidade de açúcares solúveis é aumentada, refletindo positivamente na digestibilidade. A PB na planta inteira manteve-se próxima a 1,78\%, havendo acentuada diferença entre os colmos e folhas, mas em qualquer das situações não atenderia as exigências nutricionais de bovinos, tendo-se que se lançar mão de suplementação protéica na dieta. Os níveis de açúcares mantiveram-se entre 16,4 ${ }^{\circ}$ Brix (CO 413) e 19,9 ${ }^{\circ}$ Brix (RB 76-5418). Ao considerarem os atributos qualitativos como: FDN na planta inteira menor que $52 \%$; relação FDN/Brix menor ou igual a 2,7 e a participação de colmos superior a $83 \%$, as variedades SP 71-1284, SP 79-1011, RB 76-5418 e NA 56-79 foram as mais promissoras para serem utilizadas na alimentação de bovinos.

No Amapá, Meirelles \& Mochiutti (1999) testaram nove variedades de cana (CO 419, CR 45-3, SP 71-799, SP 71-6163, SP 70-1143, RB 72-454, RB 
TOWNSEND, C.R. et al. Competição de variedades de cana-de-açúcar para a alimentação de ruminantes em Presidente Médici, Rondônia. PUBVET, Londrina, V. 6, N. 28, Ed. 215, Art. 1430, 2012.

73-9359, RB 78-5148 e RB 73-9735) e aos 17 meses de crescimento, os rendimentos médios foram de 86 t de MV/ha e de 28 t de MS/ha, com teores médios de $33 \%$ de MS, $1,5 \%$ de PB e ${ }^{\circ}$ Brix de 18 . As variedades RB 72-454, RB 78-5148 e SP 70-1143 foram as mais promissoras para serem utilizadas na alimentação de bovinos e bubalinos.

Para as condições edafoclimáticas do oeste de Santa Catarina, Rocha et al. (1998) recomendaram o cultivo das variedades RB 72-2454, RB 80-6043 e RB 76-5418, as duas primeiras em função da elevada produtividade, acima de $150 \mathrm{t}$ de $\mathrm{MV} / \mathrm{ha}$, e a terceira devido ao alto teor de sólidos solúveis e Brix superior a $18^{\circ}$. A produtividade média obtida com as seis variedades introduzidas (SP 716163, SP 71-1406 e RB 78-5750, além das já mencionadas) foi de 146 e 35 t/ha de MV e MS, com teores médios de 16\%; 3,9; 24 e 45\% de Brix, PB, MS e NDT, respectivamente. Com aumento da idade de corte $(8,10$ e 12 meses) houve incrementos nas produções de MV e MS, nos teores de Brix e MS e decréscimos nos de PB e NDT.

Neste trabalho avaliou-se o desempenho agronômico de onze variedades de cana-de-açúcar visando selecionar as mais produtivas e adaptadas às condições edafoclimáticas de Presidente Médici, Rondônia.

\section{Material e Métodos}

O ensaio foi conduzido no campo experimental da Embrapa Rondônia, localizado no município de Presidente Médici - RO (390m de altitude, $11^{\circ} 17^{\prime}$ de latitude sul e $61^{\circ} 55^{\prime}$ de longitude oeste), durante 20 meses, decorridos entre 0 final de 1999 a meados de 2001. O clima da região é do tipo Am, com precipitação anual entre 2.000 a $2.300 \mathrm{~mm}$ e estação seca bem definida (junho a setembro). A temperatura média anual é de $24,5^{\circ} \mathrm{C}$ e a umidade relativa do ar em torno de $89 \%$. O solo da área experimental foi classificado como Argissolo Vermelho-Amarelo, textura média, com as seguintes características químicas, à profundidade de 0 a $30 \mathrm{~cm}$ : pH em água $(1: 2,5)=$ 5,$2 ; \mathrm{Al}=1,1 \mathrm{cmol}_{c} / \mathrm{dm}^{3} ; \mathrm{Al}+\mathrm{H}=26,4 \mathrm{cmol}_{c} / \mathrm{dm}^{3}, \mathrm{Ca}+\mathrm{Mg}=8,6 \mathrm{cmol} / \mathrm{dm}^{3}$; $\mathrm{K}=0,79 \mathrm{cmol}_{\mathrm{c}} / \mathrm{dm}^{3}$ e $\mathrm{P}=1,0 \mathrm{mg} / \mathrm{dm}^{3}$. 
O delineamento experimental foi em blocos casualizados com três repetições. Os tratamentos consistiram de uma testemunha local de cana-deaçúcar e 10 variedades introduzidas (RB 72-454, RB 76-5418, RB 78-5148, RB 73-9359, RB 83-5486, SP 71-1406, SP 79-1011, CB 45-3, CB 47-355 e NA 5679). As parcelas foram constituídas por cinco fileiras de $8,0 \mathrm{~m}$ de comprimento com espaçamento de 1,2 m. As avaliações foram realizadas nos $6,0 \mathrm{~m}$ das três fileiras centrais.

O plantio foi realizado em novembro de 1999 em solo arado, gradeado e sulcado $(1,2 \mathrm{~m} \times 0,30 \mathrm{~m})$. Os colmos foram distribuídos, de forma a se manter pé com ponta, em densidade de 12 a 15 gemas/metro linear, sendo posteriormente seccionados. A correção do solo visou elevar a saturação por bases a 50\%. No plantio foram aplicados nos sulcos $100 \mathrm{~kg} / \mathrm{ha}$ de $\mathrm{P}_{2} \mathrm{O}_{5}$ (superfosfato triplo), $33 \mathrm{~kg} / \mathrm{ha}$ de $\mathrm{K}_{2} \mathrm{O}$ (cloreto de potássio) e $33 \mathrm{~kg} / \mathrm{ha}$ de $\mathrm{N}$ (uréia). Decorridos aproximadamente 60 e 90 dias do plantio, repetiu-se as doses de $\mathrm{K}_{2} \mathrm{O}$ e $\mathrm{N}$.

O corte foi realizado manualmente em junho de 2001, quando foram avaliados os seguintes parâmetros: florescimento do estande; acamamento do estande; altura de planta; aspectos fitossanitários, considerando-se escala de 1 (baixa incidência de pragas) a 5 (elevada incidência de pragas); concentração de sólidos solúveis ( $\left.{ }^{\circ} \mathrm{Brix}\right)$, determinada em amostra de caldo extraído de quatro colmos, utilizando-se refratômetro manual de alto contraste marca Shibuya, modelo 121; teor de matéria seca; produção de matéria verde e seca e participação dos componentes da planta (colmos, ponteiras, folhas verdes e secas).

\section{Resultados e Discussão}

A partir de abril/maio todas as variedades iniciaram o processo de pendoamento, em média o florescimento dos estandes foi de $42 \%$ (Tabela 1 ) e o menor índice (14\%) constatado com a SP $71-1406$ e o maior (67\%) com a RB 72-454, enquanto que a testemunha local obteve $40 \%$, indicando a resposta das variedades aos estímulos que induzem ao florescimento, tais 
TOWNSEND, C.R. et al. Competição de variedades de cana-de-açúcar para a alimentação de ruminantes em Presidente Médici, Rondônia. PUBVET, Londrina, V. 6, N. 28, Ed. 215, Art. 1430, 2012.

como alta temperatura, umidade e luminosidade, que ocorrem na região. Este comportamento deve ser considerado na seleção de variedades, buscando-se aquelas que apresentem menor pendoamento. Ao florescer a planta cessa a fase vegetativa, induzindo a senescência das folhas e o chochamento dos colmos, com isso, os teores de açúcar diminuem drasticamente, enquanto que os de fibra aumentam, comprometendo o valor nutritivo da cana (Matsuoka \& Hoffman, 1993).

Tabela 1. Florescimento, acamamento, altura, aspecto fitossanitário, teores de matéria seca (MS) e brix de variedades de cana-de-açúcar em Presidente Médici, Rondônia.

\begin{tabular}{|c|c|c|c|c|c|c|}
\hline \multirow{2}{*}{ Variedades } & $\begin{array}{c}\text { Floresci } \\
\text { mento }\end{array}$ & $\begin{array}{l}\text { Acama } \\
\text { mento }\end{array}$ & \multirow{2}{*}{$\begin{array}{c}\text { Altura } \\
(\mathrm{cm})\end{array}$} & \multirow{2}{*}{$\begin{array}{l}\text { Aspecto } \\
\text { fitossanitário } \\
\quad(1 \text { a } 5)^{1}\end{array}$} & \multirow{2}{*}{$\begin{array}{l}\text { MS } \\
(\%)\end{array}$} & \multirow{2}{*}{$\begin{array}{c}\text { Brix } \\
\left(^{\circ}\right)\end{array}$} \\
\hline & \multicolumn{2}{|c|}{ (\% do estande) } & & & & \\
\hline RB 72-454 & 67 & 47 & 418 & 1 & $26,0^{\mathrm{ab}}$ & $18,8^{b}$ \\
\hline RB 76-5418 & 47 & 32 & 407 & 1 & 24,4 b & $19,3^{a b}$ \\
\hline RB 78-5148 & 57 & 42 & 439 & 1 & $28,7^{a}$ & $19,3^{a b}$ \\
\hline RB 73-9359 & 17 & 52 & 411 & 1 & $26,7^{a b}$ & $18,7^{\mathrm{ab}}$ \\
\hline RB 83-5486 & 43 & 61 & 439 & 1 & $26,3^{a b}$ & $20,7^{a}$ \\
\hline SP 71-1406 & 14 & 47 & 389 & 1 & $25,7^{a b}$ & $19,7^{\mathrm{ab}}$ \\
\hline SP 79-1011 & 57 & 37 & 445 & 1 & 24,7 b & $19,3^{\mathrm{ab}}$ \\
\hline CB 45-3 & 57 & 27 & 433 & 1 & $27,3^{a b}$ & $16,5 \mathrm{~cd}$ \\
\hline CB 47-355 & 17 & 24 & 436 & 1 & 24,6 b & 17,7 bc \\
\hline NA $56-79$ & 43 & 20 & 424 & 1 & 24,5 & $19,3^{a b}$ \\
\hline "Local"2 & 40 & 35 & 349 & 1 & $19,5_{c}$ & $15,5 d$ \\
\hline Média & 42 & 39 & 417 & 1 & 25,3 & 18,6 \\
\hline Desvio Padrão & 20 & 16 & 118 & 0 & 2,6 & 1,7 \\
\hline CV (\%) & 49 & 41 & 28 & 0 & 10 & 9 \\
\hline D.M.S.(Tukey 1\%) & - & - & - & - & 3,1 & 2,0 \\
\hline
\end{tabular}

A altura média das plantas foi de $417 \mathrm{~cm}$ (Tabela 1), com a SP 79-1011 atingindo o maior porte $(445 \mathrm{~cm})$ e a testemunha o menor $(349 \mathrm{~cm})$. 0 acamamento de plantas oscilou entre 20\% (NA 56-79) e 61\% (RB 83-5486), em média 39\% das plantas acamaram (Tabela 1 ), não havendo uma relação direta entre os dois parâmetros.

Durante o ciclo vegetativo não se observou a ocorrência de pragas (Tabela 1 ). Todas as variedades receberam pontuação 1 , indicando resistência ou que a pressão de pragas e patógenos ainda é baixa no local de avaliação. 
A RB 78-5148 atingiu maiores teores de MS (28,7\%), superiores aos observados na RB 76-5418, SP 79-1011, CB 47-355, NA 56-79 (menores que $25 \%)$, que não diferiram das demais variedades introduzidas, sendo todas superiores a testemunha local $(19,5 \%)$. Estes níveis são menores que os reportados por Torres et al. (2001), Meirelles \& Mochiutti (1999) e próximos aos obtidos por Rocha et al. (1998).

Os menores níveis de sólidos solúveis, expressos em Brix, foram obtidos com a testemunha $(15,5)$ que se igualou a CB 45-3; já os maiores níveis $(20,7)$ com a variedade RB 83-5486, a qual não diferiu das variedades NA 5679, SP 79-1011, SP 71-1406, RB 73-9359, RB 78-5148 e RB 76-5418 (Tabela 1). Estes níveis são menores que os reportados por Torres et al. (2001) e próximos aos obtidos por Rodrigues et al. (1997) e Meirelles \& Mochiutti (1999), mas superiores aos descritos por Rocha et al. (1998).

Os rendimentos médios de MV e MS (Tabela 2) foram de 223 e 56 t/ha, respectivamente. A variedade $C B$ 45-3 atingiu as maiores produções (315 t de MV e 85 t de MS/ha) não diferindo em relação a MV, da RB 835486 e SP 79-1011, enquanto que a testemunha obteve os menores rendimentos ( $177 \mathrm{t}$ de $\mathrm{MV}$ e $35 \mathrm{t}$ de $\mathrm{MS} / \mathrm{ha}$ ). Estes resultados são superiores aos obtidos por Meirelles \& Mochiutti (1999), em Macapá, e Rocha et al. (1998), no oeste catarinense, e se aproximam dos obtidos por Torres et al. (2001), em Minas Gerais nas safras de 1994, 95, 96 e 98.

Em média as plantas estavam compostas por $91,4,4$ e $1 \%$ de colmos, ponteiras, folhas verdes e secas, respectivamente (Tabela 2), a testemunha apresentou a menor participação de colmos (86\%) e a NA 56-79 a maior $(95 \%)$. Todas as variedades tiveram a participação de colmos superior a $80 \%$, um dos atributos qualitativos destacados por Rodrigues et al. (1997), na seleção da cana para alimentação de ruminantes. 
TOWNSEND, C.R. et al. Competição de variedades de cana-de-açúcar para a alimentação de ruminantes em Presidente Médici, Rondônia. PUBVET, Londrina, V. 6, N. 28, Ed. 215, Art. 1430, 2012.

Tabela 2. Produção e componentes da planta de variedades de cana-deaçúcar em Presidente Médici, Rondônia.

\begin{tabular}{|c|c|c|c|c|c|c|}
\hline \multirow{3}{*}{ Variedades } & $\mathrm{MV}^{1}$ & $\mathrm{MS}^{2}$ & \multirow{2}{*}{ Colmos } & \multirow{2}{*}{ Ponteiras } & \multicolumn{2}{|c|}{ Folhas } \\
\hline & \multirow{2}{*}{\multicolumn{2}{|c|}{ (t/ha) }} & & & Verdes & Secas \\
\hline & & & \multicolumn{4}{|c|}{ (participação na planta - \%) } \\
\hline RB 72-454 & 198 bc & $51^{b c}$ & 91 & 3 & 3 & 3 \\
\hline RB 76-5418 & 210 bc & 51 bc & 92 & 3 & 4 & 1 \\
\hline RB 78-5148 & 199 bc & $54^{b}$ & 91 & 2 & 6 & 1 \\
\hline RB 73-9359 & $176^{c}$ & $46^{b c}$ & 94 & 2 & 2 & 2 \\
\hline RB $83-5486$ & $234^{\mathrm{abc}}$ & $62^{b}$ & 90 & 3 & 5 & 2 \\
\hline SP 71-1406 & $212^{b c}$ & $50 \mathrm{bc}$ & 91 & 5 & 3 & 1 \\
\hline SP 79-1011 & $262^{a b}$ & $63^{\mathrm{ab}}$ & 91 & 4 & 4 & 1 \\
\hline CB $45-3$ & $315^{a}$ & $85^{a}$ & 89 & 4 & 5 & 2 \\
\hline CB 47-355 & $250^{\mathrm{abc}}$ & $57^{b}$ & 93 & 4 & 3 & 0 \\
\hline NA 56-79 & $218^{b c}$ & $53^{b c}$ & 95 & 2 & 2 & 1 \\
\hline "Local"2 & $177^{c}$ & $35^{c}$ & 86 & 7 & 6 & 1 \\
\hline Média & 223 & 56 & 91 & 4 & 4 & 1 \\
\hline Desvio Padrão & 69 & 17 & 25 & 2 & 2 & 1 \\
\hline CV (\%) & 31 & 32 & 28 & 48 & 44 & 61 \\
\hline $\begin{array}{l}\text { D.M.S. (Tukey } \\
1 \% \text { ) }\end{array}$ & 83 & 21 & - & - & - & - \\
\hline
\end{tabular}

${ }^{1} \mathrm{MV}$ : matéria verde; ${ }^{2} \mathrm{MS}$ : matéria seca; ${ }^{3}$ Testemunha.

Médias seguidas de letras diferentes nas colunas diferem entre si (Tukey a 1\%).

\section{Conclusões}

A variedade de cana-de-açúcar SP 79-1011 se destaca das demais, pois apresenta elevada produtividade conciliada a satisfatórios teores de sólidos solúveis (açúcar) e participação de colmos superior a $80 \%$, podendo ser recomendada para cultivo nas condições edafoclimáticas de Presidente Médici, Rondônia.

\section{Referências Bibliográficas}

CAMPOS, M.M.; BORGES, A.L. da C. C.; GONÇALVES, L.C. Cana-de-açúcar na alimentação de gado de leite. In: GONÇALVEZ, L.C.; BORGES, I.; FERREIRA, P.D.S. (Ed.). Alimentos para gado de leite. Belo Horizonte: FEPMVZ, 2009. p.7-25.

COSTA, N. de L.; MAGALHÃES, J.A.; TAVARES, A.C.; TOWNSEND, C.R.; PEREIRA, R.G. de A.; SILVA NETTO, F.G. Diagnóstico da pecuária em Rondônia. Porto Velho: Embrapa-CPAF Rondônia, 1996. 34p. (Embrapa-CPAF Rondônia. Documentos, 33).

DOMINGUES, F.N.; OLIVEIRA, M.D.S.; MOTA, D.A.; FERREIRA, D. de S.; SANTOS, J. Desempenho de novilhas de corte alimentadas com cana hidrolisada. Ciência Animal Brasileira, v.13, p.8-14, 2012. 
GANEM, M. É tempo de cana: plantio bem feito e tratos culturais garantem uma maior produtividade. Revista Produtor Parmalat, v.1, n.8, p.38-42, 1997.

IDARON. Agência de Defesa Sanitária Agrosilvopastoril do Estado de Rondônia. Informe semestral de campo: referente a $31^{\circ}$ etapa de vacinação. Porto Velho, maio, 2011, não paginado.

MATSUOKA, S.; HOFFMAN, H.P. Variedades de cana-de-açúcar. In: SIMPÓSIO SOBRE NUTRIÇÃO DE BOVINOS, 5., 1993, Piracicaba, SP. Anais... Piracicaba: FEALQ, 1993. p.17-35.

MEIRELLES, P.R.L.; MOCHIUTTI, S. Avaliação do potencial de variedades de cana-de-açúcar no Amapá. In: REUNIÃO ANUAL DA SOCIEDADE BRASILEIRA DE ZOOTECNIA, 36., 1999, Porto Alegre, RS. Anais... Porto Alegre: SBZ, 1999. 3p. CD-ROM.

PEIXOTO, A.M. A cana-de-açúcar como recurso forrageiro. In: SIMPÓSIO SOBRE MANEJO DA PASTAGEM, 8., 1986, Piracicaba, SP. Anais... Piracicaba: ESALQ, 1986, p.17-47.

PINTO, A.P.; PEREIRA, E.S.; MIZUBUTI, I.Y. Características nutricionais e formas de utilização da cana-de-açúcar na alimentação de ruminantes. Semina (Ciências Agrárias), v.24, p.7384, 2003.

ROCHA, R.; MIRANDA, M.; GONDIM, P.; ORTOLAN, A. Produtividade de cultivares de cana-deaçúcar no oeste de Santa Catarina. Agropecuária Catarinense, v.11, n.1, p.8-10, 1998.

RODRIGUES, A. de A.; PRIMAVESI, O.; ESTEVES, S.N. Efeito da qualidade de variedades de cana-de-açúcar sobre seu valor como alimento para bovinos. Pesquisa Agropecuária Brasileira, v.32, n.12, p.1333-1338, 1997.

SILVA, E.A.; FERREIRA, J.J.; RUAS, J.R.M.; PAES, J.M.V.; MACEDO, G.A.R. Utilização da canade-açúcar na alimentação ruminantes. Informe Agropecuário, v.28, p.102-119, 2007.

SIQUEIRA, G.R.; ROTH, M.T.P.; MORETTI, M.H.; BENATTI, J.M.B.; RESENDE, F.D. Uso da cana-de-açúcar na alimentação de ruminantes. In: ZOOTEC 2011, 2011, Maceió. Anais... Maceió: Associação Brasileira de Zootecnia, 2011. p.1-19.

TORRES, R. de A.; RESENDE, H. Os fundamentos da cultura da cana. In: DIAS, J.C.; COSTA, J.L. (Org.). Forrageiras para o gado leiteiro. São Paulo: Tortuga; Juiz de Fora: Embrapa-CNPGL, 1997. p.101-104.

TORRES, R. de A.; COSTA, J.L.; RESENDE, H. Técnicas de alimentação. In: SEMINÁRIO REGIONAL AGRONEGOCIO LEITE, 1., 2001, Ji-Paraná, RO. Anais... Porto Velho: EmbrapaCPAF Rondônia: SEAPES-RO: EMATER-RO: SEBRAE-RO, 2001. p.102-111. 